\title{
Language Variation and the Implication for Language Teaching
}

\author{
Changjuan Zhan \\ School of Foreign Languages, Qingdao University of Science and Technology, Qingdao 266061, China \\ Email: zy15716@163.com
}

\begin{abstract}
Teaching English as a foreign language in China has many problems, among which the biggest one is students' incompetence in language use. In order to help Chinese learners have a better idea of language use, this paper takes a sociolinguistic view at language variations and offers suggestions for language teaching.
\end{abstract}

Index Terms - sociolinguistic, language variation, regional difference, social class, style

\section{INTRODUCTION}

Language, in fact, is a body of knowledge or rules, which human beings use for the purpose of communication or social activity. Since we human beings can not live without society or to be more specific, without communication with each other, so language, as a vehicle of our communication, shows its importance in society. Up to now, 'language' is regarded as a general term in our discussion. However, we might have noticed, for example, such phenomenon that speech varies considerably from region to region or from lower social class to upper social class. This is what we call 'language variation'.

\section{LANGUAGE VARIATIONS}

\section{A. Regional Differences}

This is what we most familiar with. Regional difference refers to the different use of language, such as pronunciation, lexicon or even syntax, in different areas. So we have British English, American English, Asian English, etc. in terms of microscope; and London dialect, Oxford dialect, etc. in terms of microscope. Now, let's take American English and British English as an example. The difference between American English and British English is an obvious manifestation of language variation in different areas. American English is brought in America by English immigrants. Because of geographical estrangement and political independence these immigrants seldom contact with people in their homeland. Thus their spoken English is different from that of people in their homeland, with time passing by, a regional language variant came in being-American English. In American English, if the suffix "-l" is an unstressed syllable, it should not be doubled, such as "traveler", but English people always spell it as "traveller". British people say "autumn", but Americans say "fall".

It is worth noting that the longer an area is inhabited by a population speaking the same language, the more dialect diversity we can expect to find. Thus, the differences among the various regional dialects in Britain are more than those found in such countries as the United States, Canada, South Africa, etc. Similarly, if we look at the regional differences within the United States, we see that the greatest distinctions are to be found along the eastern seaboard, the area which has been inhabited by English speakers for the longest period of time.

Although regional differences in pronunciation, lexicon and even syntax may be quite pronounced, these distinctions between the English of one area and that of another are not usually great enough to prevent mutual intelligibility, because enough linguistic structure and basic vocabulary are shared for mutual comprehension to take place. Most important of all, in the $20^{\text {th }}$ century, public education, geographic mobility and the distribution of radio, television have worked against the development of regional dialects into separate, mutually unintelligible languages.

In spite of mutual intelligibility of various dialects, there is a problem existing between dialects and Standard English. Wherever English is spoken as a native language, dialect differences will emerge. The idea of a standard is, in many respects, an abstraction rather than a concrete reality. If we accept the idea that standard speech is equivalent to the speech of the educated or the prestige group, we are left with the fact that educated people come from virtually everywhere in the English-speaking world and therefore speak in many different regional dialects. Thus, we must recognize that if we apply the notion of a standard to spoken English, we are dealing with an ideal in terms of syntax rather than with any specific model of pronunciation. In most language communities where a more or less rigid standard speech is assumed to exist, the very word 'dialect' is derogatory since it refers to an uneducated or quaint way of speaking. But, to linguists, the term 'dialect' has no such pejorative meaning since it is understood that each regional and social group has its own set of features of pronunciation, vocabulary and syntax.

When we turn to the written language, we are on much firmer ground in speaking of a standard. Although a few small differences exist in the orthographies of English and the United States, the rules for written Standard English are well 
established and vary little from region to region.

\section{B. Social Class Difference}

We all know that lower class speakers use different language forms from upper class people. It is part of the communicative competence of the native speaker to recognize differences in social class based on speech behavior. For this reason, it is important for language learners to have some familiarity with the ways in which social class is manifested in speech.

Social class differences in speech intersect with regional differences in such a way that features which are used by the prestige group in one region may well be regarded as markers of low socioeconomic status in another. A particular well known example is the pronunciation of the (r) sound after the ends of words. In England and in the Boston area of the United States, (r)-less speech is part of the pronunciation pattern of the prestige group. At present, however, the exact reverse is true. For this reason, studies which seek to investigate social class variation must focus on specific dialect areas or even speech communities.

Social class variation also has relations to Standard English and nonstandard English. It is widely accepted that upper class people speak Standard English, while lower class speakers' English is nonstandard. When you ran across the sentence: "I can't do nothing!" in the novel Uncle Tom's cabin, you may think it was misprinted. But the main character Tom in this novel is a black, uneducated person. He can only speak in this way. While the standard English should be: "I can do nothing" or "I can't do anything". So different dialects and accents are related to differences of social class background.

To put it in another way, language is heterogeneous and full of variability. One of the major factors influencing linguistic differences within a speech community is the socioeconomic background and educational level of the speakers. The variety of a language spoken by those who have wealth, power, and education is generally regarded as the prestige variety by the entire community. When the prestige variety becomes codified in written form, with dictionaries and grammar books which prescribe 'correct' usage, and when it becomes the variety used by government, courts of law, the mass media, and the school, it is referred to as the standard variety or the standard language. Once the language of the prestige group becomes codified and given official recognition in textbooks, dictionaries, and grammar books, forms which differ from it are regarded as incorrect. Since the varieties of English which are called nonstandard are those spoken by people at the lower end of the social scale, it is clear that a social rather than a linguistic distinction is at the heart of the judgment. If what the lower classes speak is considered 'bad English' because it is spoken by the lower classes, then there is really no way out of the trap except for the lower classes to learn to use the prestige or standard variety. This is the major reason it is considered important for children to be taught 'good grammar' in school.

Studies show that nonstandard varieties of English have long histories, just as the standard does, and that the same kinds of historical forces have operated to change and form both standard and nonstandard varieties of the language. It is a historical accident that certain forms of English have come to be codified and therefore to carry more prestige than others. There is nothing more or less pure about one variety of English over another. Nevertheless it must also be recognized that although the use of Standard English is not better in any objective sense than the use of any other variety, it occupies a privileged position because it is considered better by society. From a linguistic point of view, then, any variety of English which is systematic or consistent in its grammar is good English. From the point of view of society however, Standard English is the only good English. From the point of view of school achievement, we are also faced with the undeniable fact that the tests given nationwide in the United States are heavily biased in favor of middle and upper class children who come to school speaking Standard English.

\section{Style}

In many ways this is the most critical of all, since stylistic variation intersects with social class differences such that speakers speak differently depending on the social identity of their interlocutor as well as on the speech situation in which they happen to find themselves. What is important in the study of style is that no one who is communicatively competent speaks the same way all the time. While the social class and educational background of speakers will have a strong influence on speech patterns for everyone and in every situation, it is still the case that part of the communicative competence of every native speaker is the ability to alter patterns of speech behavior to suit the situation, including the identity of those who are listening. We shift styles to indicate varying degrees of social distance, for example, we do not speak the same way to intimates as we do to strangers. The speech event in which one is participating also has a very strong influence on the style of speech used. For example, the same person in a casual conversation may be addressed in a style which indicates little social distance. An hour later, involved in a professional meeting with other in attendance, the same interlocutors may use a far more formal style. On the other hand, individuals engaged in telling a personal narrative, for example, may well use very different styles when engaging in conversation with a close friend than they would use with someone who is a distant acquaintance or a total stranger.

\section{IMPLICATIONS FOR ENGLISH LANGUAGE TEACHING}

After an analysis of language variations, several suggestions can be made for Chinese English learners. First, English listening and speaking should be given more importance. Teachers could use materials relevant to daily communication 
such as recorded clips from BBC or VOA and spend at least one class a week on speaking. Second, cultural background needs to be taught together with vocabulary. This helps them to build a stable vocabulary ready for effective use.

Attention should also be paid to one of the difficult problems faced in teaching English as a foreign language, that is, the variety of English to be taught. The variety of English taught will depend heavily on who is doing the teaching. Obviously, teachers have social and regional identities and whether or not they are native speakers of English, they come from a great variety of national and geographic origins. As we have seen, languages vary greatly from region to region and, within regions, from social group to social group. Since these differences involve pronunciation, vocabulary, and syntax, it is clear that not all English teachers can be expected to present all students of English with the same linguistic model on which to pattern their speech. So, for us, as foreign learners, we should try our best to learn English well, but we may never reach native-like English. It is nothing to be regretful, as long as we are able to communicate with native English speakers well, our English study then, cannot be regarded as an unsuccessful one.

\section{REFERENCES}

[1] Fasold, Ralph.( 1990). The Sociolinguistics of Language. Oxford: Blackwell Publisher Ltd, 120

[2] Hudson, R. (1996). Sociolinguistics. Cambridge: Cambridge University Press, 78-79.

[3] Montgomery, M. (2008). An Introduction to Language and Society. New York: Routledge, 87-90.

[4] Ronald Wardhaugh. (2000). An Introduction to Sociolinguistics. Beijing: Foreign Language Teaching and Research Press, 48.

[5] Spolsdy, B. (1998). Sociolinguistics. New York: Oxford University Press, 3.

[6] Trudgill, P. (1983). On Dialect: Social and Geographical Perspective. Oxford: Basil Blackwell, 57-61.

[7] Wolfson, Nessa. (1989). Perspectives: Sociolinguistics and TESOL. New York: Newbury House Publishers, 114-115.

[8] Kangmei, Zhang. (2001). Sociolinguistics on Language Teaching. Basic Medicine Education, 3, 199-200.

[9] Ying, Zhang (2000). Sociolinguistics and TESOL. Foreign Language Teaching, 2, 53-55.

Changjuan Zhan was born in Longkou, Shandong Province, China in 1963. She is currently an associate professor in the School of Foreign Languages, Qingdao University of Science and Technology, Qingdao, China. Her research interests include teaching methods and second language acquisition. 